
\title{
25 Research Square \\ Functional Finishing of Polyester Fabric With Polystyrene-acrylic/zno Nanocomposite for Effective Dyes Filtration
}

Mariia Pasichnyk ( $\sim$ pasechnik86@gmail.com )

V.O. Sukhomlynskyi National University of Mykolaiv

Miroslava Václavíková

Institute of Geotechnics Slovak Academy of Sciences

Jana Gaálová

Institute of Chemical Process Fundamentals of the CAS

Inna Melnyk

Institute of Geotechnics Slovak Academy of Sciences

Peter Minarik

Charles University

\section{Research Article}

Keywords: Methyl Orange (MO), Methylene Blue (MB), FTIR, SEM analysis, functionalised layer

Posted Date: September 22nd, 2021

DOI: https://doi.org/10.21203/rs.3.rs-908093/v1

License: (c) (i) This work is licensed under a Creative Commons Attribution 4.0 International License. Read Full License 


\section{Abstract}

Organic dyes such as Methyl Orange (MO) and Methylene Blue (MB) are widely used in different industries, becoming one of the leading emerging water contaminants. It is urgent to develop the most suitable materials for effective elimination of the dyes as they are non-biodegradable and are not removed efficiently by the traditional treatment methods.

The present work applied polystyrene-acrylic/ZnO nanocomposite on the polyester surface by blade coating and one-bath pad methods. Features of surface chemical modifications were determined by FTIR, SEM analysis, WCA, $\mathrm{N}_{2}$ adsorption-desorption isotherms. The functionalised layer can create unprecedented function of filter textile material depending on the way of treatment. The possibility of using such fabrics as filters was explored for $\mathrm{MO}$ and $\mathrm{MB}$ in the concentration of $100 \mathrm{ppm}$. Water purification occurred by $60 \%$ from methylene blue and $40 \%$ from methylene orange flowing through the padded polyester filter and the covered polyester filter for $2 \mathrm{~min}$, respectively. Moreover, it was shown that a colourless reduced form of MB - leuco-methylene blue (LMB) could be created. The functionalised layer of the developed filters through hydrogen bonding between the $-\mathrm{OH}$ groups of styrene-acrylic molecules and the $-\mathrm{N}\left(\mathrm{CH}_{3}\right)_{2}$ groups on LMB can stabilise LMB.

\section{Introduction}

Water pollution by industrial effluent like organic dyes is now one of the critical issues worldwide. The growing concentration of dyes pollutants in water is hazardous and causes significant environmental problems due to the reducing the photosynthetic activity and oxygen enrichment of aquatic organisms by decreasing light transmittance ${ }^{1}$.

Various physicochemical approaches have been made to remove the dyes from water, such as chemical precipitation ${ }^{2}$, filtration ${ }^{3}$, and coagulation and flocculation processes ${ }^{4}$. Filtration is one of the easiest ways to remove pollutants from wastewater. The development and implementation of new types of filters with higher filtering capabilities have great importance.

Polymer nanocoated textiles can show good results as water filters due to the material's high physical and mechanical resistance ${ }^{5}$. By controlling the finishing processes of the textile material, it is easy to create the required porosity and possible to increase the filter life and save material facilities. Nanofillers in the polymer composition can provide high durability for fabrics because nanoparticles have a large surface area-to-volume ratio and high surface energy, thus presenting better fabric affinity and increasing durability ${ }^{6}$. Furthermore, was investigated the photoactivity of modified textiles in the decontamination of organic dyes 7,8 and degradation of gaseous pollutants ${ }^{9}$. Moreover, the nanoparticles can penetrate into certain parts of the substrate, such as pores, holes, and crevices, and they lock mechanically to the substrate. Where the voids between the nanoparticles can be utilised as filtration channels, as a result, filtration performance can be increased. 
Currently, the production of photoactive textiles incorporated with photocatalytic particles is of great interest. Considerable research devoted to the preparation and investigation of such materials impregnation of textiles in the dip-coating method. Han and Bai immobilised different layers of titanium dioxide onto the surface of polypropylene fabric. They confirmed that methyl orange dye solution degradation under UV and visible lights could be greatly improved over one layer of titanium dioxide coating. Also, such fabrics can be used for the photocatalytic oxidation of phenol from water ${ }^{10}$.

Zhang and Zhu immobilised Fe-doped $\mathrm{TiO}_{2}$ on the surface of polyamide fabric under hydrothermal conditions. Coating demonstrated improved photocatalytic activity against methylene blue ${ }^{11}$. $\mathrm{Ag}-\mathrm{TiO}_{2}$ was synthesised by photo-reducing $\mathrm{Ag}^{+}$ions to Ag metal and then coated on cotton fabric using the paddry-cure method. The coated fabric showed high efficiency against methylene blue under the normal laboratory environment conditions ${ }^{12}$.

In the present work, polymer composition for the finishing of polyester textile was created by mixing acrylic copolymer, melamine cross-linked agent and $\mathrm{ZnO}$ nanoparticles. Polyester material was treated by polymer composition using coating and padded method. Developed textile material was used in the filtration of organic dyes from the model wastewater.

\section{Materials And Methods}

\section{Materials}

Aqueous dispersion of thermally linking styrene-acrylic copolymer (Tubifast 4010R, CHT, Switzerland: dry residue $45 \%, \mathrm{pH}=7-9$, viscosity at $20^{\circ} \mathrm{C}<500 \mathrm{mPa} \square$ s) was used as polymer matrix.

Partially esterified melamine resin (TubifixR, CHT, Switzerland: density $1.15 \mathrm{~g} / \mathrm{cm} 3, \mathrm{pH}=8.5-10.5$, viscosity at $23^{\circ} \mathrm{C} 200 \mathrm{mPa} \square \mathrm{s}$ ) was used as a cross-linking agent.

Sodium 4-alkyl-2ylbenzenesulfonate (Sulfanol, Germany: dry residue $75 \%, \mathrm{pH}=8-9$ ) was used as surfactant (SAS).

$\mathrm{ZnO}$ nanoparticles were synthesized by direct precipitation method ${ }^{16}$ using zinc acetate $\left(\mathrm{Zn}\left(\mathrm{CH}_{3} \mathrm{COO}\right)_{2} \cdot \mathrm{H}_{2} \mathrm{O}\right)$ (p.a., $99 \%$, Centralchem, Slovakia) and sodium carbonate $\mathrm{Na}_{2} \mathrm{CO}_{3}$ (p.a., $99 \%$, Centralchem, Slovakia).

Polyester textile material (China, surface density $=460 \pm 30 \mathrm{~g} / \mathrm{m}^{2}$, bursting load, $\mathrm{N}$ length/width $=$ $1100 / 1200$, bursting elongation, $\%$ length width $=25 / 30$, breathability $=130 \mathrm{dm} 3 / \mathrm{m} 2 \mathrm{~s}$, heat resistance $\left.180^{\circ} \mathrm{C}\right)$.

Methylene blue, $\mathrm{C}_{16} \mathrm{H}_{18} \mathrm{CIN}_{3} \mathrm{~S}$ (MB, 95\%, microCHEM). Methyl orange, $\mathrm{C}_{14} \mathrm{H}_{14} \mathrm{~N}_{3} \mathrm{NaO}_{3} \mathrm{~S}(\mathrm{MO}, 95 \%$ microCHEM). 


\section{Methods}

\section{Finishing polyester method}

Polymer compositions with $\mathrm{ZnO}$ nanoparticles were used for treatment of polyester fabric by two methods: one bath pad method and blade coating method. For this purpose two different composition were developed (Table 4).

Table 4

Prepared polymer nanocomposition

\begin{tabular}{|ll|}
\hline Composition for one bath pad method & Composition for covering method \\
\hline - Styrene-acrylic copolymer - 50 \% & - Styrene-acrylic copolymer $65 \%$ \\
- Partially esterified melamine - 5\% & - Partially esterified melamine $25 \%$ \\
- ZnO nanoparticles - $10 \%$ & - ZnO nanoparticles $10 \%$ \\
- SAS (Sulfanol) $1 \%-35 \%$ & \\
\hline
\end{tabular}

The covering was implemented by the blade coating method. As shown in Fig. 14, the polymer composition is applied to the fabric while being run at tension under a floating knife blade. The distance between the fabric and the knife was $1 \mathrm{~mm}$, which determines the thickness of the coating. The polymer composition had to be highly viscose to prevent soaking through the fabric. The coating was dried under $100^{\circ} \mathrm{C}$ for 30 minutes to fix the covering on the polyester surface. This sample was labelled as covered polyester.

The padding technique, widely regarded as a textile finishing technique, usually refers to a fibre coating to apply micro or nanomaterials or chemical compositions. As shown in Fig. 15, the fabric was submerged in the polymer composition for $90 \%$ pick-up and then dried at $100^{\circ} \mathrm{C}$ for 30 minutes. This sample was labelled as padded polyeste.

\section{Water absorption test}

The sample was dried first at $38.5^{\circ} \mathrm{C}$ to get a constant weight, noted as $\mathrm{W}_{0}(\mathrm{~g})$. Then immersed the samples in deionized water for $1 \mathrm{~h}$, took out the fabric and absorbed the surface water droplets with filter papers (the whole process should take no more than $1 \mathrm{~min}$ ), weighted the fabric and recorded as $\mathrm{W}_{1}(\mathrm{~g})$. The water adsorption capacity of fabric was calculated by the following equation:

$W=\frac{\left(W_{1}-W_{0}\right)}{W_{0}} * 100$

\section{Thickness and surface density}

The areal density PA (g/m2) was calculated according to Eq. (1): 


$$
\mathrm{Pa}=\frac{\mathrm{m}}{\mathrm{A}}
$$

where $\mathrm{m}$ is mass $(\mathrm{g})$ measured by an electronic balance, and $\mathrm{A}$ is area $(\mathrm{m} 2)$.

Fourier transform infrared (FTIR) spectrum of produced filters was recorded with the help of spectrometer Avatar 360 (Nicolet) in the range of 508 and $4000 \mathrm{~cm}-1$ (resolution $1.93 \mathrm{~cm}-1,200$ scans, $1 \mathrm{~s}$ per scan).

Microstructure investigation were performed by a scanning electron microscope (SEM) ZEISS Auriga Compact equipped with EDAX energy-dispersive X-ray spectroscope (EDS) and field emission scanning electron microscopy MIRA 3 FE-SEM microscope (TESCAN, Czech Republic) equipped with a highresolution cathode (Schottky field emitter) and with three-lens Wide Field Optics ${ }^{\text {TM }}$ design.

A filtration study was carried out with a textile filter when $25.0 \mathrm{ml}$ (100 ppm solutions) of dye at pH $\sim 6.0$ in a dynamic mode moved through the filter with an average speed of $0,21 \mathrm{ml} / \mathrm{sec}$. The concentration of dyes was measured on a Helios Gamma UV-vis spectrophotometer (Thermo electron corporation, UK) for $\mathrm{MB}$ in the region $200-700 \mathrm{~nm}$ and $\mathrm{MO}-300-600 \mathrm{~nm}$. Filtration was conducted by the vacuum filtration method (Fig. 16), using a Buchner porcelain funnel and filtration glass flask. According to this technique, a dye solution was vacuum-filtered through produced filters. The water from the funnel penetrates the filter and flows into a conical beaker by reducing the pressure with a water pump.

The amount of dye adsorbed onto the fabric surface at equilibrium, $Q_{\mathrm{e}}(\mathrm{mg} / \mathrm{g})$, was calculated by the following expression:

$$
Q_{e}=\frac{\left(C_{0}-C_{e}\right) V}{M m}
$$

where $C_{0}$ and $C_{e}$ are the initial and equilibrium dye concentrations in $\mathrm{mg} / \mathrm{L}$ respectively, $V$ is the volume of solution $(\mathrm{L})$ and $m$ is the mass of the filter $(\mathrm{g})$.

The filtration efficient (retention in \%) was calculated by the following:

$$
R=\frac{\left(C_{0}-C\right)}{C_{0}} * 100 \%
$$

where $\mathrm{C}_{0}$ is the mass concentration of dyes in the upstream, and $\mathrm{C}$ is the mass concentration of dye in the downstream.

\section{Results}

The structure and properties of the yarn and fabric were optimised considering the characteristics of filter fabrics (Table 1). Different types of surface treatment of polyester lead to different types of etching due to chemical modification. The surface becomes smooth, which leads to deterioration of wettability. 
Table 1

Structure characteristics of filters.

\begin{tabular}{|llllll|}
\hline & $\begin{array}{l}\text { Mass of } \\
\text { filter, } \mathbf{g}\end{array}$ & $\begin{array}{l}\text { Mass of } \\
\text { composition, } \mathbf{g}\end{array}$ & $\begin{array}{l}\text { Thickness, } \\
\mathbf{m m}\end{array}$ & $\begin{array}{l}\text { Area } \\
\text { density, } \\
\mathbf{g} / \mathbf{m}^{2}\end{array}$ & $\begin{array}{l}\text { Bulk density, } \\
\mathbf{g} / \mathbf{c m}^{3}\end{array}$ \\
\hline Polyester & 0.72 & - & 0.315 & 128 & 2.28 \\
\hline $\begin{array}{l}\text { Padded } \\
\text { polyester }\end{array}$ & 0.87 & 0.14 & 0.333 & 155 & 2.61 \\
\hline $\begin{array}{l}\text { Covered } \\
\text { polyester }\end{array}$ & 1.08 & 0.36 & 0.340 & 192 & 3.17 \\
\hline
\end{tabular}

The Finishing process happens due to the mechanism shown in Fig. 1. Partially esterified melamine can be linked covalently to polyester fabrics and styrene-acrylic binder by curing at $140-150{ }^{\circ} \mathrm{C}$ through transamidation. At these temperatures, the primary amino groups of the melamine can react with the carboxylic acids groups of styrene-acrylate and with accessible ester groups at the surface of the polyester fibre.

Polymer matrix and textile material can stabilise nanoparticles. Such stabilisation provides fixing the nanoparticles to each other or fixing the particle layer on the support layer. Such treatment enabled a diversity of textile materials and their pore geometries. High flow resistance is possible during filtration if the particles used as fillers are selected by size.

Surface chemical modifications of finished polyester fabric were determined by an FTIR analysis in the range of $500-4000 \mathrm{~cm}^{-1}$. Figure 2 shows the FTIR spectra obtained for the untreated polyester, padded polyester and covered polyester. In untreated polyester, the presence of ester, alcohol, anhydride, aromatic ring, and heterocyclic aromatic rings can be seen. An absorption peak at the wavelength of $1710 \mathrm{~cm}^{-1}$ is related to the stretching vibration of the carbonyl group $(C=0)$, the peak at $700 \mathrm{~cm}^{-1}$ attributed to the out-of-plane bending vibration of the $\mathrm{C}-\mathrm{H}$ on the benzene ring, and the peak at $1014 \mathrm{~cm}^{-1}$ is assigned $\mathrm{O}-\mathrm{H}$ out-of-plane bending in terminal carboxylic groups ${ }^{13}$. This is a reason that there is still alcohol and anhydride as residual reactants left in the polyester. The carboxyl, ester, anhydride and alcohol groups showed that the polyester fabric was not pure. There is not much change in the padded polyester since the intensity and position of absorption peaks were not changed too much. Cleary can be seen an absorption bend of $\mathrm{C}=\mathrm{O}$ vibration is shifted to the left $\left(1760 \mathrm{~cm}^{-1}\right)$, indicating the adhesion of acrylic acid on the surface, and it introduced carboxyl groups ${ }^{14}$. Covered polyester shown an absorption peak at $2957 \mathrm{~cm}^{-1}$ assigned to stretching vibration of $\mathrm{C}-\mathrm{H}$ groups, intensive band at $1449 \mathrm{~cm}^{-1}$ is due to bending vibrations of $-\mathrm{CH}_{2}$ groups; the band at $1162 \mathrm{~cm}^{-1}$ corresponds to stretching vibrations of $\mathrm{C}-\mathrm{O}-\mathrm{C}$, which indicates the self-cross-linking in the polymer composition on the surface of polyester due to the etherification of carboxyl groups. The wavelength of $C=0$ shifts to the left $\left(1729 \mathrm{~cm}^{-1}\right)$, indicating the increase in the absorption intensity due to the introduction of acidic groups. Also, the proportion of the 
oxygen-containing groups such as $\mathrm{C}=\mathrm{O},-\mathrm{C}-\mathrm{OH}$ and $-\mathrm{COOH}$ increased on the surface of the treated fabric. These results may be attributed to the fact that active groups of polymer nanocomposite react with active $-\mathrm{O}-\mathrm{C}=\mathrm{O}$ (carboxylic) groups of polyester fabric, resulting in the formation of oxygencontaining polar groups on the fabric surface. The introduction of oxygen-containing polar groups on the fabric surface changes the nature of the surface. Evidently, the intensity of peaks of covered polyester is sharpened over the untreated and padded, indicating acrylic acid makes bonding with polyester fibres in the process.

The observed absorption bands (Fig. 2b, c) at $608.6 \mathrm{~cm}^{-1}$ indicate the stretching vibrations of $\mathrm{Zn}-\mathrm{O}$ in the covered and padded polyester sample, so it signifies that the $\mathrm{ZnO}$ nanoparticles are presented ${ }^{15}$.

\section{Water absorption test}

Water absorption (retention) test results of the filter materials are given in Fig. 3. The standard polyester fabric absorbs a minimal amount of water $(0.8 \%)$ into its structure. Water absorption decreases dramatically at padded polyester. Polymer nanocomposite applied to the polyester surface made a significant contribution to the water absorbency of filter media. It was detected that the differences between the water absorption values of padded and covered polyester occurred because of the low adsorption property of the polymer composition that is due to their ability to decrease the porous diameter and change fabric structure.

\section{The structure of the surfaces}

The structure of the coated surfaces was characterized by scanning electron microscopy (SEM). The SEM images were used to investigate the change in the surface morphology of the untreated, padded and covered polyester fabric, as shown in Fig. 4 (A-C). The surface of untreated polyester $(A)$ is smooth and distinct. The polyester surface becomes rough due to the applying of the polymer nanocomposite. The surface of the covered polyester consists of big particles of unmixed acrylic dispersion, that's why pores are not regular (B). The padded polyester (C) shows a drastic change in the fibre surface morphology, with the presence of voids and pores. On the surface of padded polyester, single $\mathrm{ZnO}$ nanoparticles can be clearly seen. The wires are flatter, as they are covered by polymer composition.

The SEM images show that the structure of treated polyester is relatively bulky, and the structure of the polymer composition is relatively dense. Due to the fact that polymer composition consists of $\mathrm{ZnO}$ nanoparticles, on the surface of textile can be formed cross-linked structure which has crosslinked units with components of composition and polyester fibres. As a result, the structure became crisscross and intertwined, so the filter pore size decreased. This factor can't be ignored, as the combination of polymer nanocomposite surface and polyester substrate will increase the filtration resistance and improve the filtration efficiency. Produced layer decreases the possibility for the penetration of the dye molecules into the fibres and lets them rather adsorbed on the surface. 
The result of the elemental mapping performed on the surface of the padded polyester fabric sample is shown in Fig. 5. The nanoscale ZnO particles can be clearly seen well distributed on the surface of polyester. The particle size plays a primary role in determining their adhesion to the fibre. It is reasonable to expect that the largest particle agglomerates will be easily removed from the fibre surface. In contrast, the smaller particles in the polymer composition will penetrate deeper and adhere strongly to the fabric matrix.

\section{Hydrophobicity}

Hydrophobicity improved by modification of the filters using polymer composition. The results of the studied filters are shown in Fig. 6 . When the polyester textile material was deposited with polymer composition, the contact angle was dramatically increased, indicating that the hydrophobicity of the surface was greatly improved.

Untreated textile material exhibits poor hydrophobicity with water contact angle (WCA) $30.6^{0}$. Covered polyester has good hydrophobic properties, with a measured WCA of $100.0^{0}$. Padded polyester has poor hydrophilic properties WCA $60.8^{0}$.

This finding is in contradiction with the results of polymer nanocomposite film formed on the glass surface reported in previous studies. The polymer film exhibit smoothness surface ${ }^{16}$. Polyester fabric is characterised by hairiness which forms an unregular surface. As the polymer film texture is created on the surface of textile fiber, polymer nanocomposite build-up hierarchical structures and increases surface roughness ${ }^{17}$, which significantly improve the hydrophobic properties of treated polyester fabric ${ }^{18}$. The primary reason that produced filters realises hydrophobicity is that polluted water droplets can be stably supported on the hierarchical structure of the filter surface, and dyes could form pockets in the interface.

\section{Low-temperature nitrogen adsorption-desorption isotherms}

Figure 7 shows the nitrogen adsorption-desorption isotherms obtained at $77 \mathrm{~K}$ for polyester textile material prepared with different treatment techniques. The covered and padded polyester exhibit steep type III isotherms, indicating the occurrence of macroporous. Additionally, the development of mesoporosity is indicated by the pronounced desorption hysteresis loops that appear for samples. Covered polyester shows a wide hysteresis loop, and the desorption curve is steeper than the adsorption branch, indicating that the samples have various pore types and pore diameter distributions. Padded polyester characterised with narrow hysteresis loop. Meanwhile, untreated polyester shows open-wedge pores.

The surface areas of the filter available to the nitrogen vapour were calculated according to the BET equation. The calculated surface area values are presented in Table 2. It is pointed out that the surface area available to the nitrogen vapour is greatly dependent upon the way of polyester treatment. Polymer nanocomposite film was also tested and showed a non-porous structure with low specific surface values 
of $8.7 \mathrm{~m}^{2} / \mathrm{g}$. A small hysteresis loop can be seen, which indicates the presence of some pores or holes in the network.

Table 2

Characteristics of the produced filters surface

\begin{tabular}{|llll|}
\hline & $\begin{array}{l}\text { Surface area } \\
\mathbf{S}_{\mathrm{BET}}, \mathbf{~ m}^{2} / \mathbf{g}\end{array}$ & Total pore volume $\mathbf{V}_{\text {tot }} \mathbf{c m}^{3} / \mathbf{g}$ & Pore size, $\mathrm{nm}$ \\
\hline Polyester & 5.9 & 0.036 & 3.4 \\
\hline Padded polyester & 85.2 & 0.065 & 3.4 \\
\hline Covered polyester & 44.6 & 0.028 & 3.1 \\
\hline Polymer composition & 8.7 & - & - \\
\hline
\end{tabular}

\section{Pore Size Distribution}

The proper selection of filter material is an essential factor in achieving efficient filtration. Pore size measurements Fig. 8 shows the distribution of the pore size.

The average pore size of untreated polyester is $\sim 3.4 \mathrm{~nm}$, covered polyester is $\sim 3.08 \mathrm{~nm}$, and padded polyester is $\sim 3.4 \mathrm{~nm}$. Total pore volume is $0.036 \mathrm{~cm}^{3} / \mathrm{g}, 0.028 \mathrm{~cm}^{3} / \mathrm{g}$ and $0.065 \mathrm{~cm}^{3} / \mathrm{g}$, respectively. The pore size of covered polyester is smaller compared with untreated and padded polyester. Moreover, the average pore size of untreated polyester is the same as padded. Two more maximums of pore distribution $4.2 \mathrm{~nm}$ and $12.4 \mathrm{~nm}$ at padded polyester, indicate that pores are not regular. The surface of the polyester substrate consists of a large number of fibres that can interweave and pile up with each other, contributing to the formation of some large pores between the fibres. On the other hand, the accumulation of fibres on the surface may result in partial blockage of the pores and, therefore, some small pores formed. ${ }^{19}$

\section{Filtration experiment}

The possibility of using such fabrics for filters was explored with methylene blue and methyl orange solution. The size of the methylene blue molecule is around $13.82 \AA^{20}$. The methyl orange molecules have a larger size $\sim 26.14 \AA^{21}$. Considering the length of the dyes molecules and the dimension of the pores in filters, organic dyes can easily enter into the pores. It was shown that the concentration of $\mathrm{MB}$ decreased from $100 \mathrm{ppm}$ to $60 \mathrm{ppm}$ using the padded polyester, and the content of $\mathrm{MO}$ declined from $100 \mathrm{ppm}$ to $40 \mathrm{ppm}$ assisting the covered polyester (Fig. 9-10). These observations indicate that organic dyes of different nature can be effectively removed from the water by using the suitably processed textile filter. It is evident that the covered technology almost totally encloses the pores. Meanwhile, padded technology decries the ratio between fibres and form the solid covering of the pores. 


\section{Filtration efficiency}

It was noticed that thru the filtration process, the movement of the dyes particles typically deviates from the water flow, especially as they approach the fibre. During the filtration Brownian diffusion, the electrostatic effect and the gravity effect happened. The electrostatic effect firmly attaches the particles to the surface of the fibres. Results are presented in Table 3.

Table 3

Results of filtration of organic dyes.

\begin{tabular}{|c|c|c|c|c|c|}
\hline & \multirow{2}{*}{$\begin{array}{l}\mathrm{pH} \\
\mathrm{ZPC}\end{array}$} & \multicolumn{2}{|l|}{$M B$} & \multicolumn{2}{|l|}{ MO } \\
\hline & & $\begin{array}{l}\text { Equilibrium quantity that } \\
\text { can adsorb on the filter } \\
\mathrm{mg} / \mathrm{g} \text { in } \\
\mathrm{t} 120 \mathrm{sec}\end{array}$ & $\begin{array}{l}\text { Removal } \\
\text { rate (R), } \\
\%\end{array}$ & $\begin{array}{l}\text { Equilibrium quantity } \\
\text { adsorb on the filter } \\
\mathrm{mg} / \mathrm{g} \\
\text { in } \\
\mathrm{t} 120 \mathrm{sec}\end{array}$ & $\begin{array}{l}\text { Remova } \\
\text { rate (R), } \\
\%\end{array}$ \\
\hline Polyester & 6.81 & 0.69 & 20 & 0.520 & 15 \\
\hline $\begin{array}{l}\text { Padded } \\
\text { polyester }\end{array}$ & 6.29 & 1.14 & 40 & 1 & 35 \\
\hline $\begin{array}{l}\text { Covered } \\
\text { polyester }\end{array}$ & 6.65 & 0.81 & 35 & 0.92 & 60 \\
\hline
\end{tabular}

\section{Discussion}

Used technology for treating polyester fabric provides a unique method to lower the energy barrier between the polymer nanocomposition and the filter surface and thus increase the deposition of dyes particles on the surface of the filter. Unionised dyes molecules diffuse through the covered and padded filter because both polymer matrix and dye are hydrophobic. Moreover, pores are covered with polymer composition in padded polyester, which increases the filter adsorption capacity. In covered polyester, all interactions can happen on the surface of the filter. Furthermore, in covering technology, polymer nanocomposition cover the pores, which two times reduce their size (Fig. 11 ).

The $\mathrm{pH}$ of the dye solution was 6.00 , which is below the $\mathrm{pH}$ ZPC of the surface of treated polyester. The surface of developed filters exhibits basic properties (Table 3). Decreasing the $\mathrm{pH}$ of the surface indicates an increase in the concentration of $\mathrm{H}+$ ions in the solution. Padded polyester with $\mathrm{pH}$ ZPC 6.3 releasing $\mathrm{H}$ + ions induces a positive charge on the terminal nitrogen of the methyl orange. The positively charged terminal group in methyl orange helps in adsorption through the anion-exchange mechanism. The maximum dye removal efficiency of $\mathrm{MO}$ using covered polyester could be attributed to the electrostatic attraction between positively charged surfaces $\left(\mathrm{ZnOH}^{+}\right) .{ }^{22,23}$. 
It was recognized that the removal efficiency of $\mathrm{MB}$ is lower than $\mathrm{MO}$ due to the bigger size of $\mathrm{MB}$ anions. Some MB anions could be excluded because of the filters 'sieve effect', others could be adsorbed on the surface of the filter by an electrostatic attraction. lon exchange mechanism can be created between the nitrogen of the amino groups of $\mathrm{MB}$, the nitrogen of the $-\mathrm{NH}_{2}$ group of melamine in polymer composition and oxygen of the carbonyl group of the styrene-acrylate.

\section{Methyl orange b)Methylene blue}

Figure 12. Possible mechanism of interaction

Most researchers were focused on detecting the highly coloured form of $\mathrm{MB}$; meanwhile, its colourless reduced form, leuco-methylene blue (LMB), has not been the subject of much interest. In this article, we report the results of the formation of $L M B$, which was previously not considered when determining the adsorption properties of materials. Such observations are not surprising, as the LMB is colourless and weakly absorbs in the near UV range and absorbs more strongly in the far UV (I max $=256 \mathrm{~nm}$ ).

Several works reported chemical transformation between the highly coloured oxidised form of $\mathrm{MB}$ and its stable colourless reduced LMB. In that time, the system's colour changed from blue to colourless, corresponding to the hydrogenation of MB to LMB. MB to LMB was reduced using ascorbic acid 2425 , acrylate media ${ }^{26}$ an ionic liquid ${ }^{27}$ and nitrogen environment. Well known, MB is characterized by two main peaks one at $662 \mathrm{~nm}$ due to the substitution of the $\mathrm{N}\left(\mathrm{CH}_{3}\right)_{2}$ group on the heteroaromatic ring (responsible for colour), and the other at $292 \mathrm{~nm}$, associated with localized bands of the unsaturated heteroaromatic system.

Results of filtration with the developed filters show that the intensity of these peaks markedly decreased. Also, the spectra showed an increase in the peak at $246 \mathrm{~nm}$, which is responsible for LMB formation. Filtration with a covered polyester observed the disappearance of the absorption band associated with LMB $(246 \mathrm{~nm})$ and the formation of a hypsochromic shift up to $225 \mathrm{~nm}$. This observation further confirmed that the MB molecules were mineralised during the filtration instead of discoloured ${ }^{28}$. In this case, probably occurred the injection of electrons into the $\mathrm{ZnO}$ nanoparticles on the surface of the filte ${ }^{29}$.

Using the filter produced from padded polyester, it is observed that the original blue colour of the dye disappeared and formed a colourless LMB. The spectrum shows a steady decrease in two absorption maximum ( 664 and $292 \mathrm{~nm}$ ) and the appearance of a new band at $246 \mathrm{~nm}$ due to the formation of LMB (Fig. 13).

For a pure polyester filter, a decrease in the optical density of the dye is also observed but not so significant. The filters were inactive for $M B$ recovery to $L M B$. In the absence of the polymer composition on the filter surface, there was no marked decrease in the absorption of the dye.

The problem of detecting MB dye is that the colourless LMB can quickly switch back to the original blue colour MB through a hydrogenation/oxidation reaction mechanism when the system is exposed to 
oxygen or air. In the case of developed filters, styrene-acrylic copolymer can stabilise LMB through hydrogen bonding between the $-\mathrm{OH}$ groups of styrene-acrylic molecules and the $-\mathrm{N}\left(\mathrm{CH}_{3}\right)_{2}$ groups on $L M B$, and then efficiently slow down the fast recolouration process (oxidative dehydrogenation process) at ambient conditions ${ }^{30}$.

In conclusion, a cost-effective and straightforward process successfully fabricated two types of new textile nanocomposite filters.

The main findings of this study are listed below:

- It is indicated developed filters were fabricated with suitable thickness, lightweight property and great flexibility for practical application.

- Microstructure observation revealed that the way of polymer nanocomposite applying changed the pore structure in the filter material. Using the covered method, pores diameter decreased, which is attributed to the formation of polymer nanocomposite covering on the surface of polyester textile material. The padded method didn't reduce the pore size, moreover, polymer nanocomposition seeps all the textile material.

- Due to the hydrophobic property of produced filters, the dyes molecules would be absorbed on the surface of the filter, which led to high removal efficiency.

- It was shown that in the time of using methylene blue dye, a colourless reduced form of methylene blue - leuco-methylene blue could be created. The functionalised layer of the developed filters can stabilise leuco-methylene blue, keep it colourless and don't let it switch on back to methylene blue form.

\section{Declarations}

\section{Acknowledgements}

This research was supported by the Visegrad Scholarship Program of the Visegrad Fund (application number ID \# 52010756), APVV-19-0302 and VEGA 2/0156/19 projects, Czech Science Foundation grant №19-08153Y.

\section{Author contributions statement}

M.P. conceived the experiments, M.P., P.M., I.M. and M.V. conducted the experiments, M.P., I.M. and J.G analysed the results, M.P. and I.M. writing the draft. All authors reviewed the manuscript.

\section{Competing interests}

The author(s) declare no competing interests.

\section{Data Availability}


All data generated or analysed during this study are included in this published article (and its Supplementary Information files)

\section{References}

1. Farhan Hanafi, M. \& Sapawe, N. A review on the water problem associate with organic pollutants derived from phenol, methyl orange, and remazol brilliant blue dyes. Materials Today: Proceedings, doi:https://doi.org/10.1016/j.matpr.2021.01.258 (2021).

2. Kumar, R. \& Pal, P. Response surface-optimized Fenton's pre-treatment for chemical precipitation of struvite and recycling of water through downstream nanofiltration. Chem. Eng. J, 210, 33-44 https://doi.org/10.1016/j.cej.2012.08.036 (2012).

3. Power plant in Sweden uses water treatment system incorporating NX Filtration's hollow-fibre NF membranes. Membrane Technology 2021, 1, doi:https://doi.org/10.1016/S0958-2118(21)00050-1 (2021).

4. Lv, M. et al. Roles of magnetic particles in magnetic seeding coagulation-flocculation process for surface water treatment. Separation and Purification Technology, 212, 337-343 https://doi.org/10.1016/j.seppur.2018.11.011 (2019).

5. Zhao, H. et al. Robust sandwich micro-structure coating layer for wear-resistant conductive polyester fabrics. Appl. Surf. Sci, 494, 969-976 https://doi.org/10.1016/j.apsusc.2019.07.103 (2019).

6. Phuong, N. et al. Nano sand filter with functionalized nanoparticles embedded in anodic aluminum oxide templates. Sci. Rep, 6, 37673 https://doi.org/10.1038/srep37673 (2016).

7. Jawad, A. H., Alkarkhi, A. F. M. \& Mubarak, N. S. A. Photocatalytic decolorization of methylene blue by an immobilized TiO2 film under visible light irradiation: optimization using response surface methodology (RSM). Desalination and Water Treatment, 56, 161-172 https://doi.org/10.1080/19443994.2014.934736 (2015).

8. Shinde, D. R., Tambade, P. S., Chaskar, M. G. \& Gadave, K. M. Photocatalytic degradation of dyes in water by analytical reagent grades $\mathrm{ZnO}, \mathrm{TiO} 2$ and SnO2: a comparative study. Drink. Water Eng. Sci, 10, 109-117 https://doi.org/10.5194/dwes-10-109-2017 (2017).

9. Hussein, F. \& Abass, T. A. Photocatalytic Treatment of Textile Industrial Wastewater. international journal of chemical sciences, 8, 1353-1364 (2010).

10. Han, H. \& Bai, R. Highly effective buoyant photocatalyst prepared with a novel layered-TiO2 configuration on polypropylene fabric and the degradation performance for methyl orange dye under UV-Vis and Vis lights. Separation and Purification Technology, 73, 142-150 https://doi.org/10.1016/j.seppur.2010.03.017 (2010).

11. Wang, J., Zhao, J., Sun, L. \& Wang, X. A review on the application of photocatalytic materials on textiles. Text. Res. J, 85, 1104-1118 https://doi.org/10.1177/0040517514559583 (2014).

12. Hebeish, A. A., Abdelhady, M. M. \& Youssef, A. M. TiO2 nanowire and $\mathrm{TiO} 2$ nanowire doped Ag-PVP nanocomposite for antimicrobial and self-cleaning cotton textile. Carbohydr. Polym, 91, 549-559 
https://doi.org/10.1016/j.carbpol.2012.08.068 (2013).

13. Guo, M. X., Bian, S. W., Shao, F., Liu, S. \& Peng, Y. H. Hydrothermal synthesis and electrochemical performance of $\mathrm{MnO} 2 /$ graphene/polyester composite electrode materials for flexible supercapacitors. Electrochim. Acta, 209, 486-497 https://doi.org/10.1016/j.electacta.2016.05.082 (2016).

14. Meng, L. et al. Surface carboxyl-activated polyester (PET) fibers decorated with glucose carbon microspheres and their enhanced selective adsorption for dyes. Journal of Physics and Chemistry of Solids, 123, 378-388 https://doi.org/10.1016/j.jpcs.2018.08.005 (2018).

15. Xiong, G., Pal, U., Serrano, J. G., Ucer, K. B. \& Williams, R. T. Photoluminesence and FTIR study of ZnO nanoparticles: the impurity and defect perspective. physica status solidi c, 3, 3577-3581 https://doi.org/10.1002/pssc.200672164 (2006).

16. Pasichnyk, M., Václavíková, M. \& Melnyk, I. Fabrication of polystyrene-acrylic/ZnO nanocomposite films for effective removal of methylene blue dye from water. Journal of Polymer Research, 28, 56 https://doi.org/10.1007/s10965-021-02418-z (2021).

17. Li, X. et al. Waterproof-breathable PTFE nano- and Microfiber Membrane as High Efficiency PM2.5 Filter. Polymers, 11, 590 (2019).

18. Zahid, M., Mazzon, G., Athanassiou, A. \& Bayer, I. S. Environmentally benign non-wettable textile treatments: A review of recent state-of-the-art. Advances in Colloid and Interface Science, 270, 216250 https://doi.org/10.1016/j.cis.2019.06.001 (2019).

19. Xin, Q. et al. Electrospinning in membrane contactor: manufacturing Elec-PVDF/SiO2 superhydrophobic surface for efficient flue gas desulphurization applications. Green Chemical Engineering, 2, 111-121 https://doi.org/10.1016/j.gce.2020.10.011 (2021).

20. Jia, P., Tan, H., Liu, K. \& Gao, W. Removal of Methylene Blue from Aqueous Solution by Bone Char. Applied Sciences 8 1903, doi:10.3390/app8101903 (2018).

21. Danish, M., Hashim, R., Ibrahim, M. \& Sulaiman, O. Characterization of Physically Activated Acacia mangium Wood-Based Carbon for the Removal of Methyl Orange Dye. BioResources 8 , doi:10.15376/biores.8.3.4323-4339 (2013).

22. Majumdar, S., Saikia, U. \& Mahanta, D. Polyaniline-Coated Filter Papers: Cost Effective Hybrid Materials for Adsorption of Dyes. Journal of Chemical \& Engineering Data, 60, 3382-3391 https://doi.org/10.1021/acs.jced.5b00645 (2015).

23. Tanzifi, M. et al. Adsorption of Amido Black 10B from aqueous solution using polyaniline/SiO2 nanocomposite: Experimental investigation and artificial neural network modeling. Journal of Colloid and Interface Science, 510, 246-261 https://doi.org/10.1016/j.jcis.2017.09.055 (2018).

24. Snehalatha, T., Rajanna, K. C. \& Saiprakash, P. K. Methylene Blue - Ascorbic Acid: An Undergraduate Experiment in Kinetics. Journal of Chemical Education, 74, 228 https://doi.org/10.1021/ed074p228 (1997).

25. Lee, S. K. \& Mills, A. Novel photochemistry of leuco-Methylene Blue. Chem. Commun, 2366-2367 https://doi.org/10.1039/B307228B (2003). 
26. Galagan, Y. \& Su, W. F. Reversible photoreduction of methylene blue in acrylate media containing benzyl dimethyl ketal. Journal of Photochemistry and Photobiology A: Chemistry, 195, 378-383 https://doi.org/10.1016/j.jphotochem.2007.11.005 (2008).

27. Kadokawa, J., Izawa, H., Ohta, T., Wakizono, S. \& Yamamoto, K. Photo-Induced Reduction Reaction of Methylene Blue in an Ionic Liquid. International Journal of Organic Chemistry Vol, 01 No.04 (4), https://doi.org/10.4236/ijoc.2011.14023 (2011).

28. Islam, M. A. et al. Adsorption and UV-Visible Light Induced Degradation of Methylene Blue over ZnO Nano-Particles. International Journal of Chemical Reactor Engineering, 9 , https://doi.org/10.1515/1542-6580.2278 (2011).

29. Trandafilović, L. V., Jovanović, D. J., Zhang, X., Ptasińska, S. \& Dramićanin, M. D. Enhanced photocatalytic degradation of methylene blue and methyl orange by $\mathrm{ZnO}$ :Eu nanoparticles. Appl. Catal. B, 203, 740-752 https://doi.org/10.1016/j.apcatb.2016.10.063 (2017).

30. Liu, Y. N. et al. Hydrogenation/oxidation induced efficient reversible color switching between methylene blue and leuco-methylene blue. RSC Advances, 7, 30080-30085 https://doi.org/10.1039/C7RA04498D (2017).

\section{Figures}

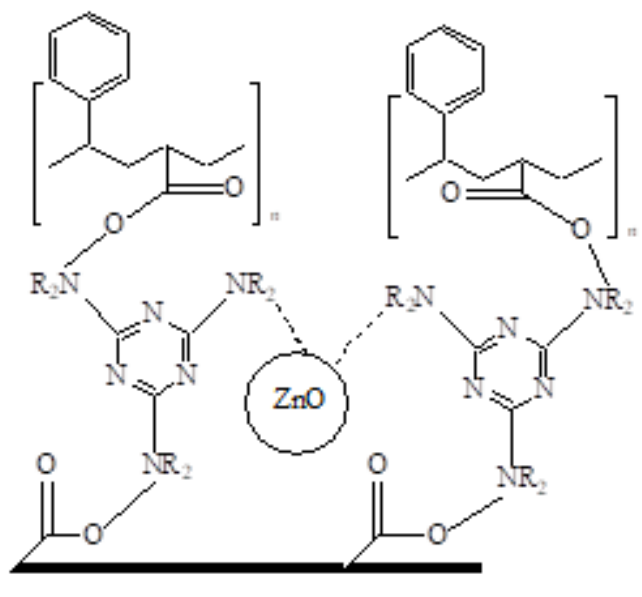

polyester fabric

\section{Figure 1}

Scheme of the polyester finishing of by polymer nanocomposition. 


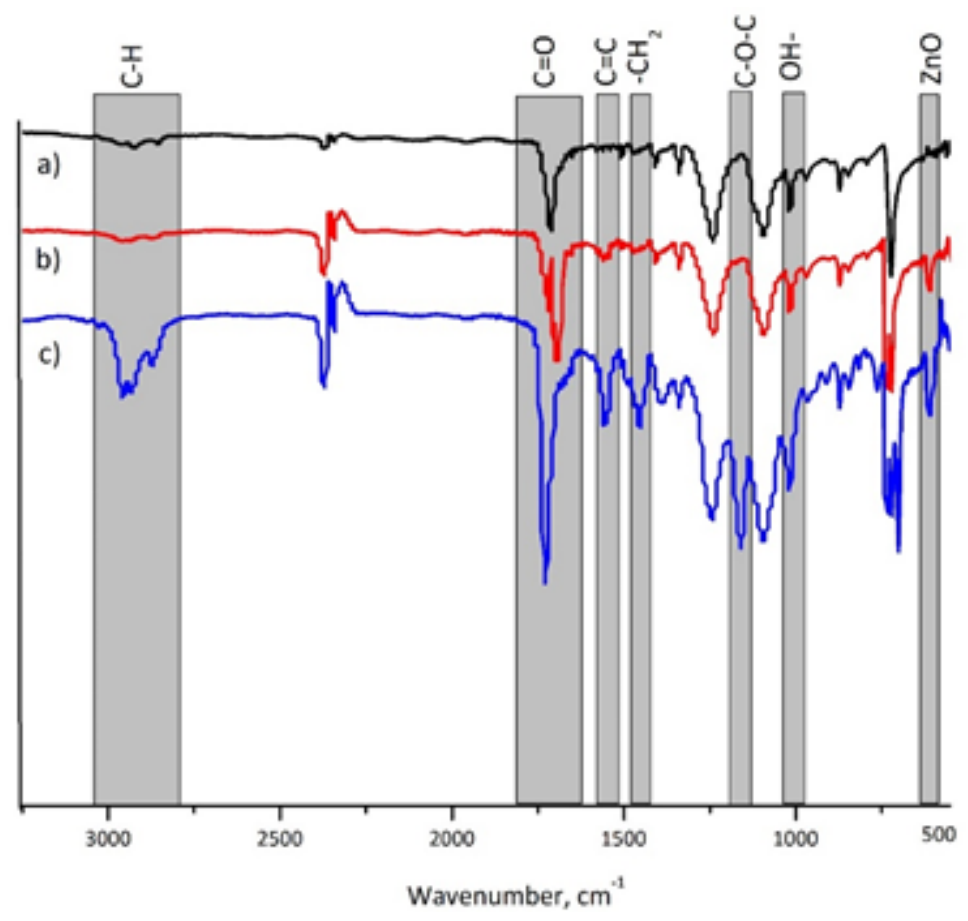

Figure 2

FTIR spectra of a) Polyester; b) Padded polyester; c) Covered polyester.

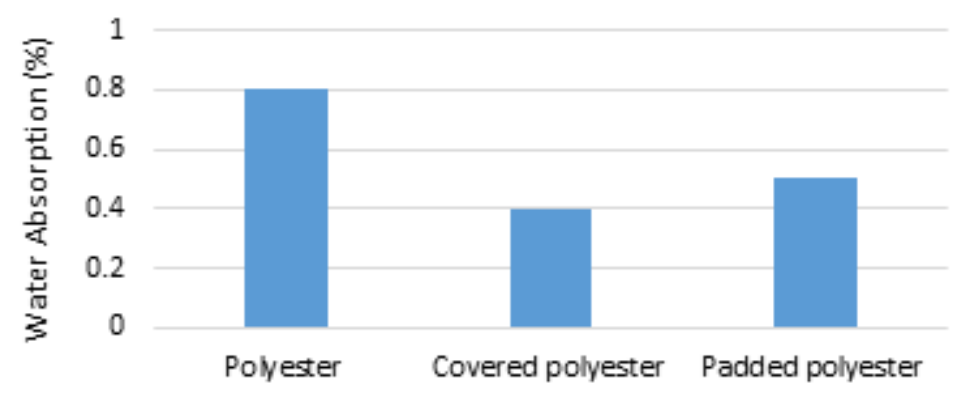

Figure 3

Water absorption test. 


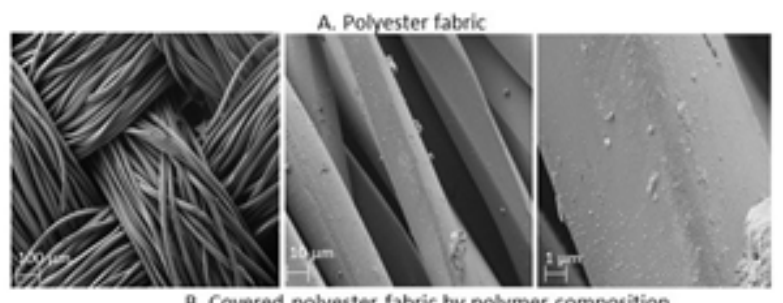

B. Covered polyester fabric by polymer composition

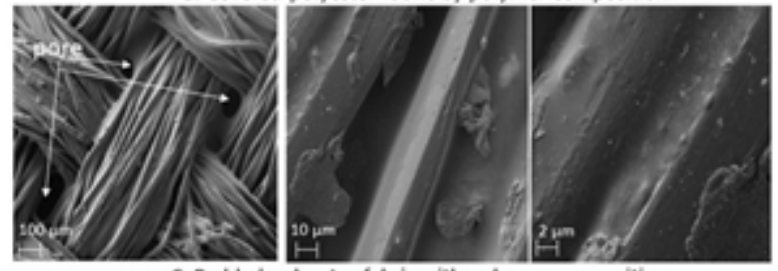

C. Padded polyester fabric with polymer composition

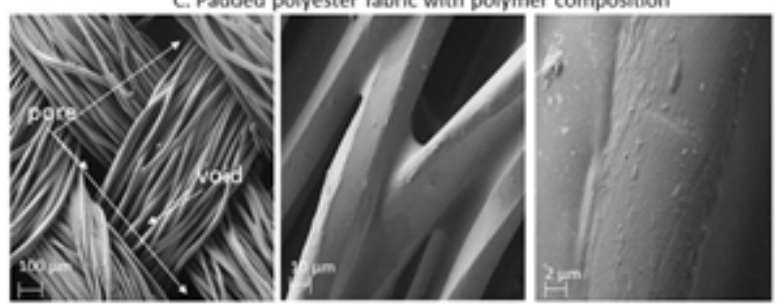

Figure 4

SEM image of the samples.
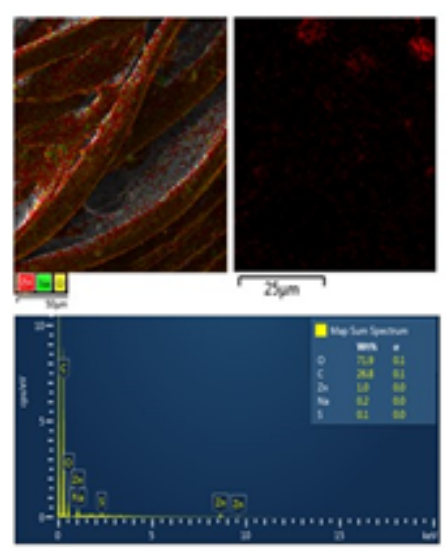

Figure 5

EDS layer images of the padded polyster.
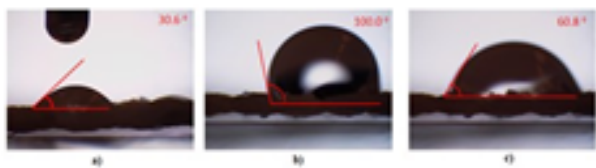

Figure 6

The optical image of water contact angle (a) untreated polyster (b) covered polyster (c) padded polyster 

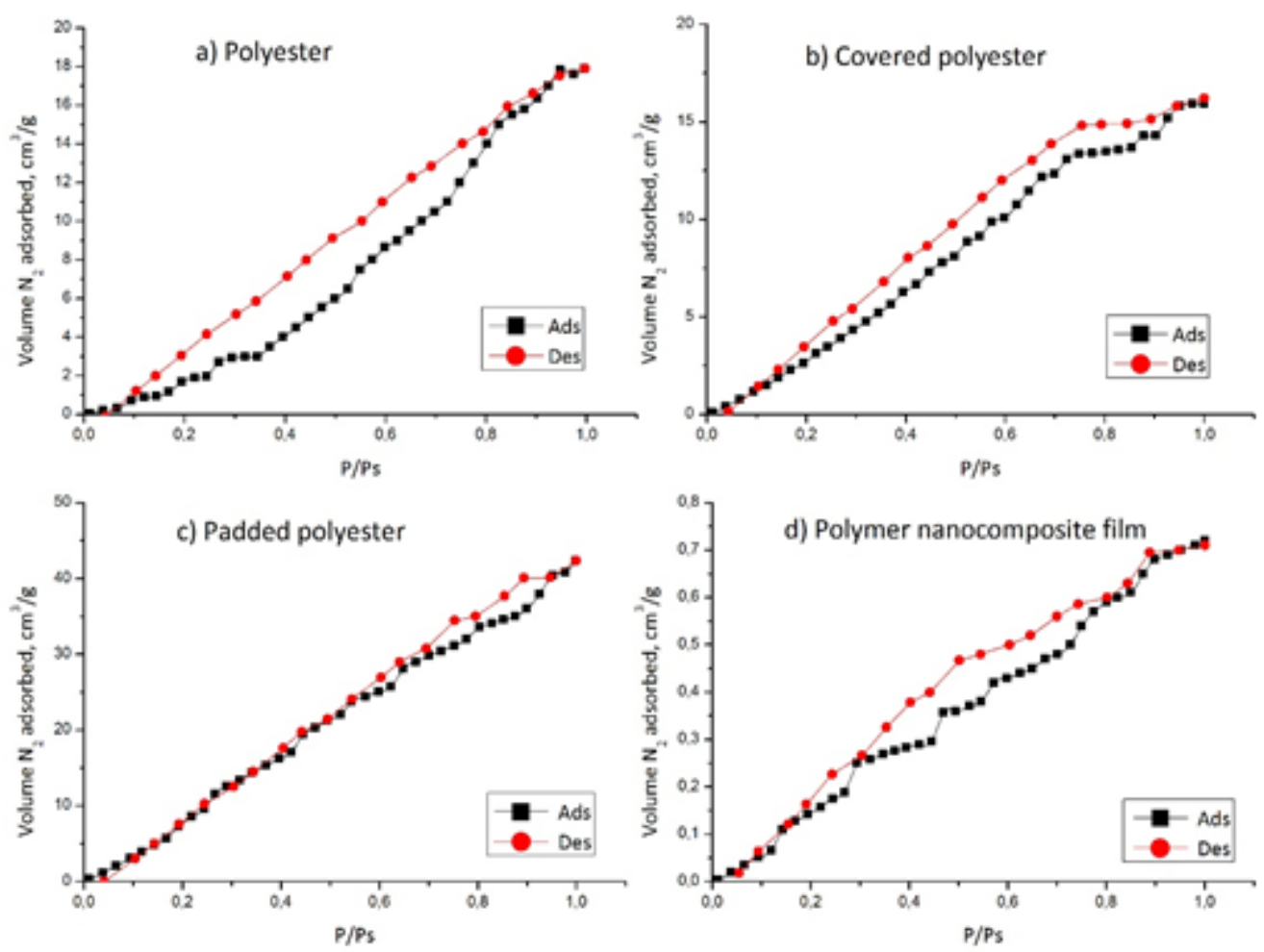

\section{Figure 7}

Nitrogen adsorption-desorption isotherms

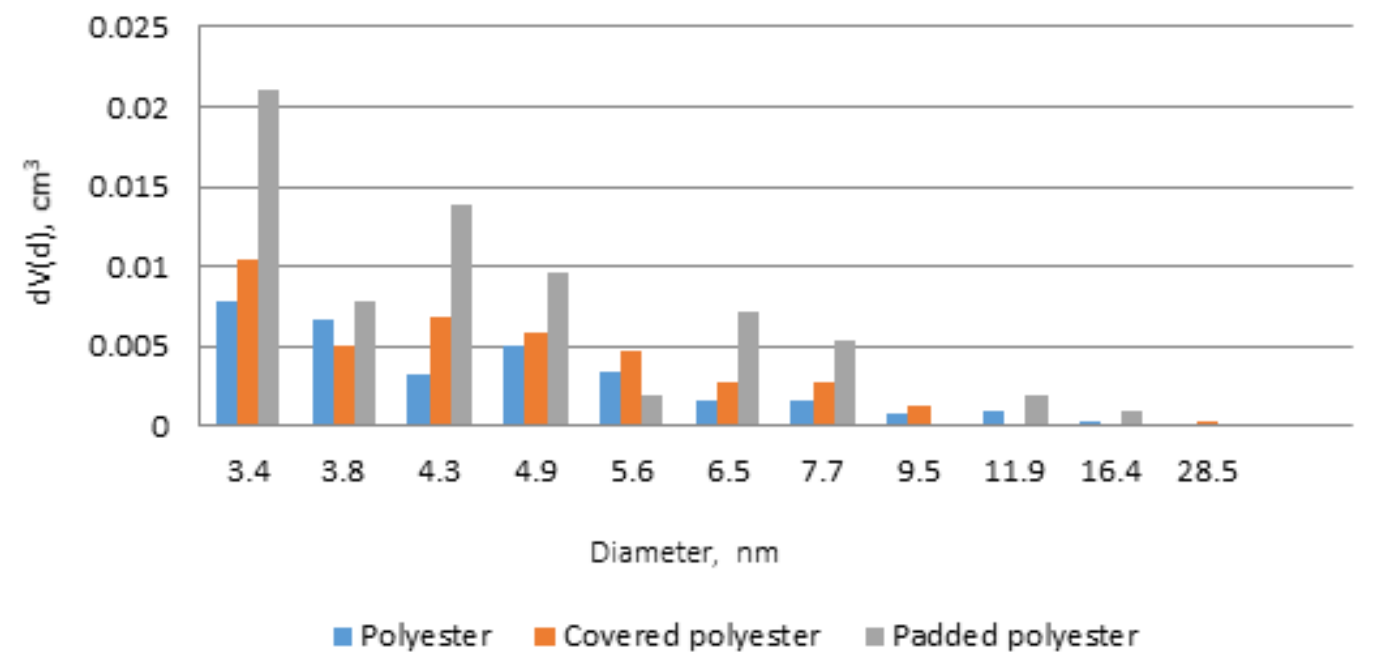

Figure 8

Pore size distribution 

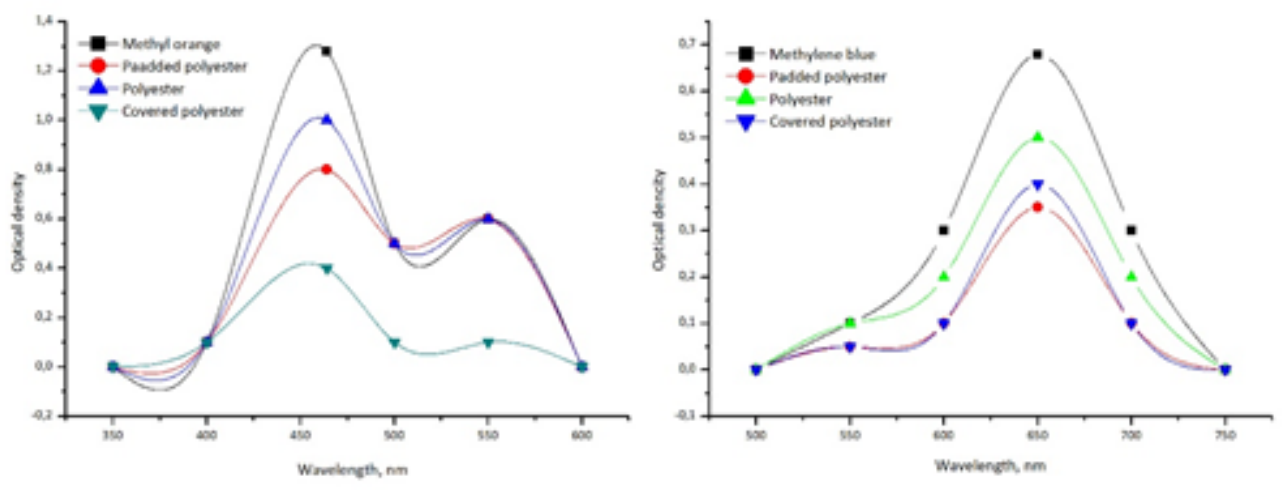

Figure 9

UV-Visible spectra of methylene blue (a) and methyl orange (b) initial solution and solutions after filtration

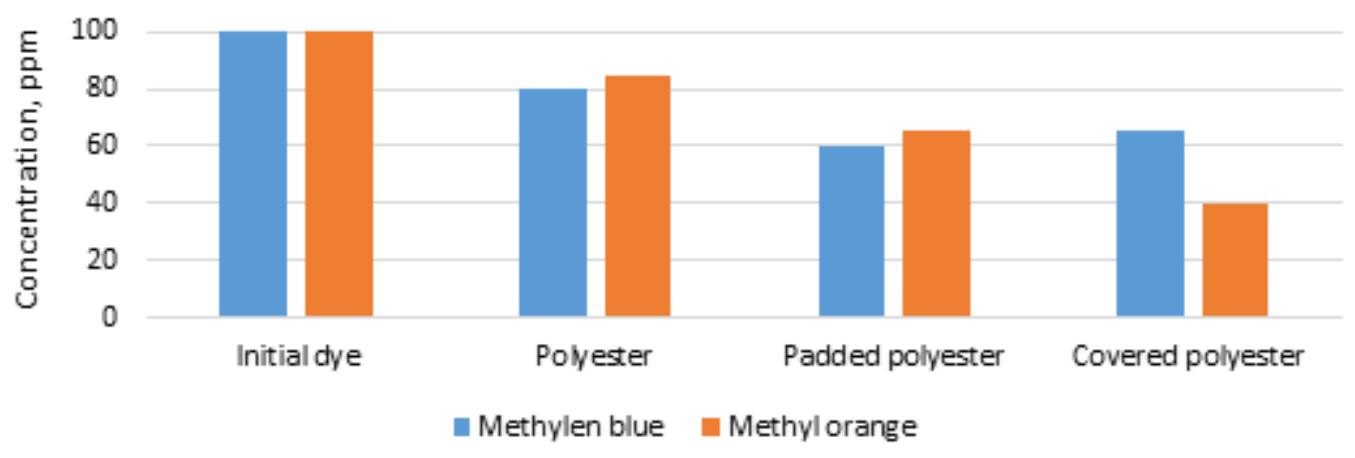

Figure 10

Concentration of organic dyes after filtration

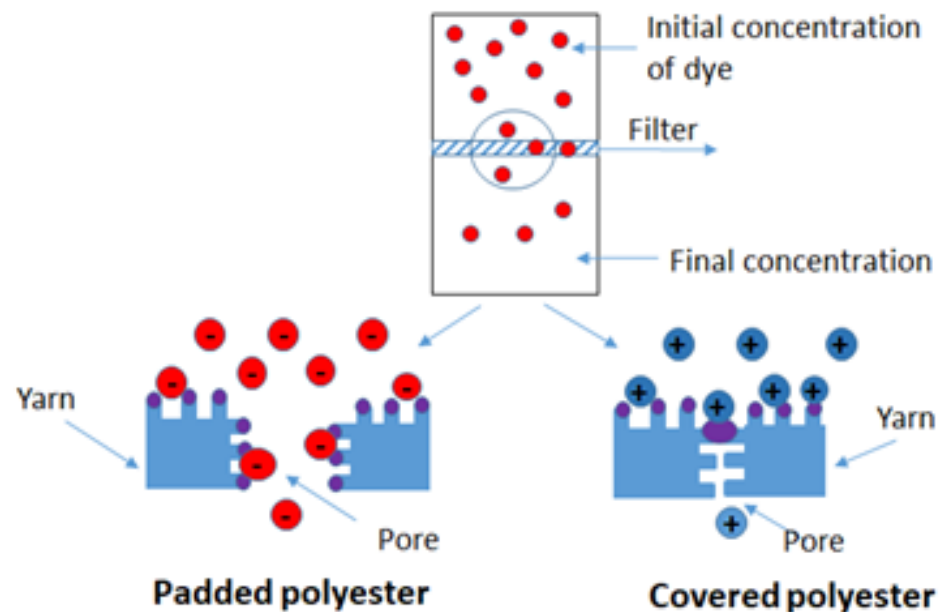

Figure 11

Scheme of produced filters 


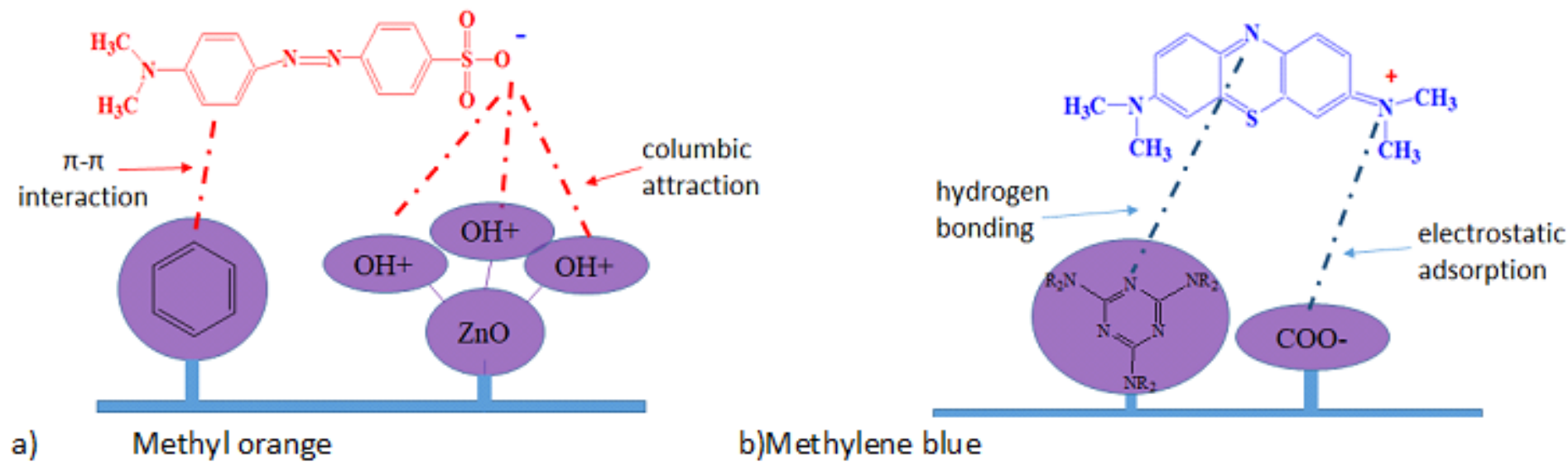

Figure 12

Possible mechanism of interaction

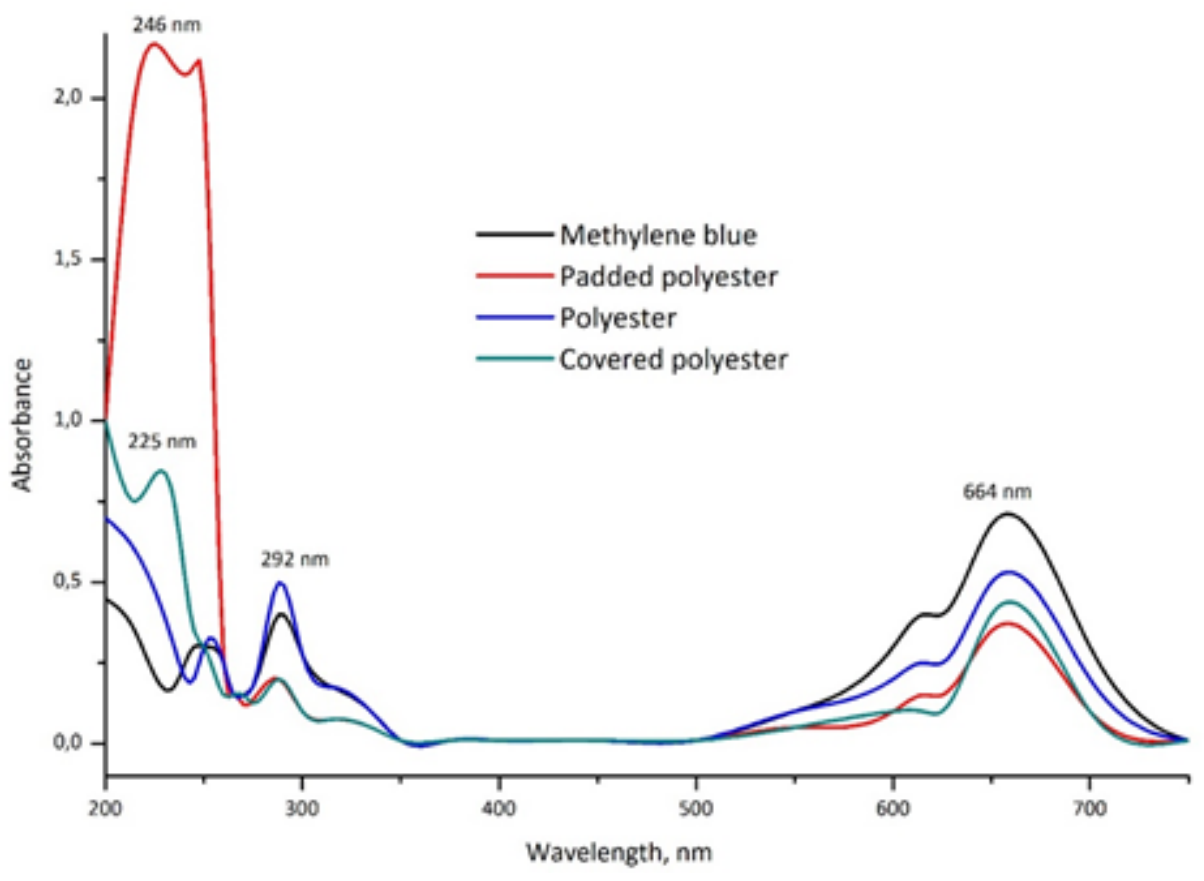

Figure 13

UV/vis spectra recorded for methylene blue solution before and after filtration

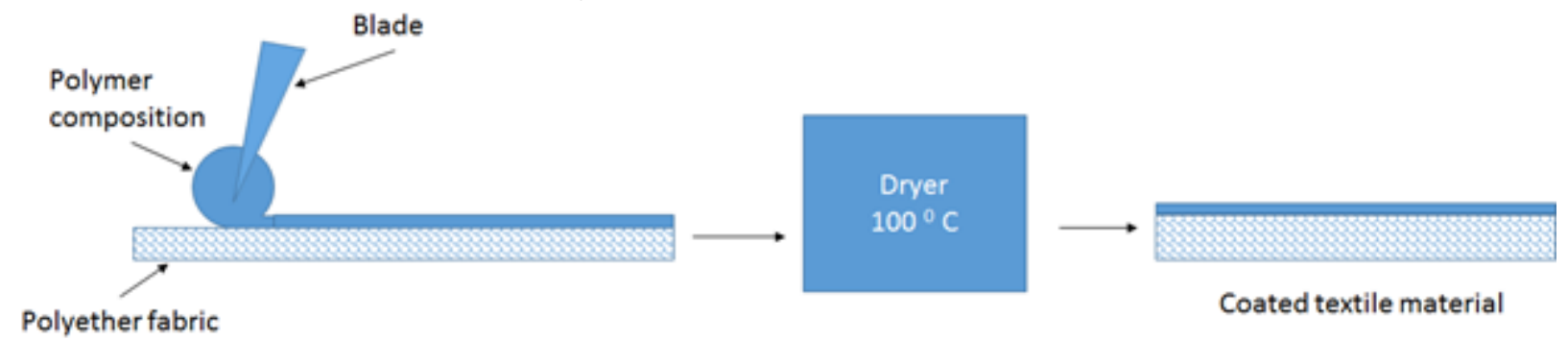

Figure 14 
The Blade coating method (covering of polyester)
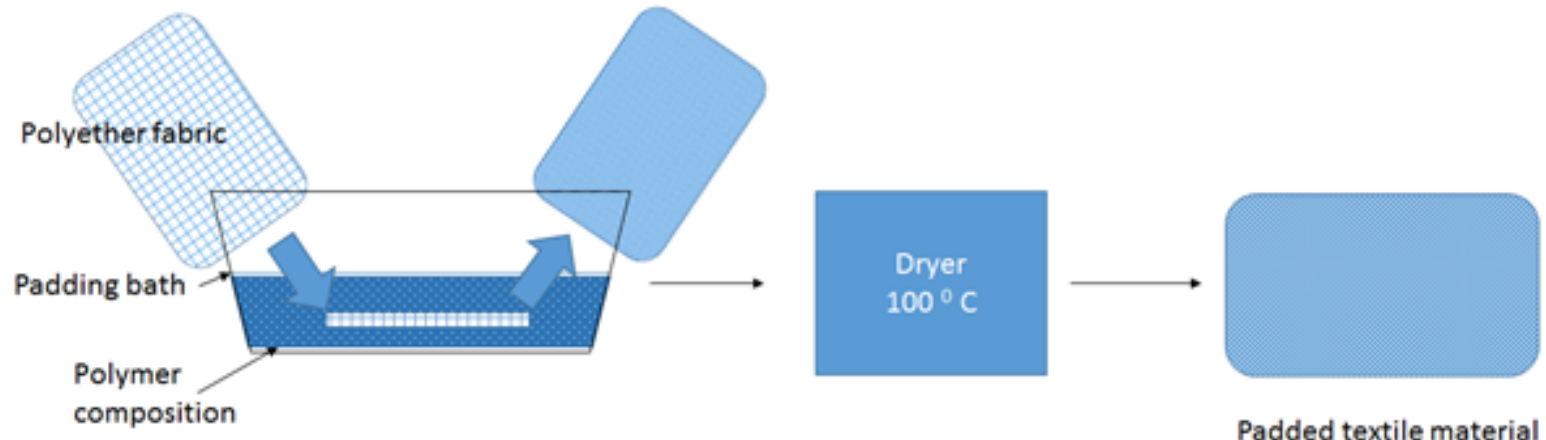

Padded textile material

Figure 15

One-bath pad method

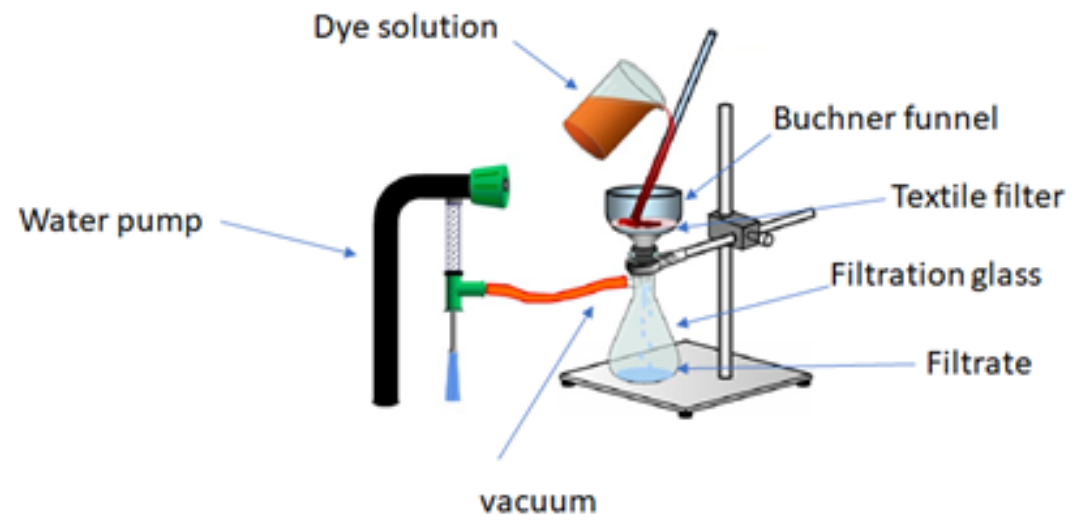

Figure 16

Vacuum filtration method 